\title{
Development of a primary-care tool to assess treatment success in COPD: consensus report from a closed meeting of respiratory and primary-care specialists
}

\author{
Jim Reid a,*, David Price ${ }^{\mathrm{b}}$, Thys van der Molen ${ }^{\mathrm{c}}$, Bruno Housset ${ }^{\mathrm{d}}$, \\ José Jardim ${ }^{\mathrm{e}}$, Paul Jones ${ }^{\mathrm{f}}$, Peter Kardos ${ }^{\mathrm{g}}$, Jean-François Muir ${ }^{\mathrm{h}}$, \\ Pierluigi Paggiaro ${ }^{i}$, Stephen Rennard ${ }^{j}$, Emiel Wouters ${ }^{k}$
}

a University of Otago, Dunedin, New Zealand

b University of Aberdeen, King's College, Aberdeen AB24 3FX, UK

' University of Groningen, Groningen, The Netherlands

d CHU de Créteil, France

e Federal University of São Paulo, São Paulo, Brazil

f St George's Hospital Medical School, London, UK

${ }^{g}$ Maingau Hospital, Frankfurt, Germany

${ }^{\mathrm{h}} \mathrm{CHU}$ de Rouen, Hôpital de Bois Guillaume, France

i University of Pisa, Pisa, Italy

${ }^{j}$ University of Nebraska Medical Center, Lincoln, USA

${ }^{\mathrm{k}}$ University of Maastricht, Maastricht, The Netherlands

Received 23 December 2003; accepted 13 March 2004

KEYWORDS

Primary-care;

COPD;

GOLD
Summary A 1-day meeting, attended by invited respiratory and primary-care specialists all of whom had an international profile and a specific interest in Chronic Obstructive Pulmonary Disease (COPD), considered specific research recommendations from the Global Initiative in Obstructive Lung Disease (GOLD) workshop report. Attendees discussed developing a tool to complement spirometry and help primary-care physicians assess treatment success in patients with chronic obstructive pulmonary disease. Discussion focused on the requirement of such a tool, and the limitations of existing tools. Proposals followed for a simple, cost-effective checklist for primary-care. This paper is a consensus report of the discussions from the meeting. Decisions reached on the proposed questionnaire were unanimous.

(c) 2004 General Practice Airways Group. Published by Elsevier Ltd. All rights reserved.
*Corresponding author. Present address: Department of General Practice, Dunedin School of Medicine, Great King Street, Dunedin, New Zealand. Tel.: +64-3-479-7446; fax: +64-3-479-7431.

E-mail address: jim.reid@stonebow.otago.ac.nz (J. Reid).

\section{Introduction}

The Global Initiative for Obstructive Lung Disease (GOLD) aims to increase awareness of Chronic Obstructive Pulmonary Disease (COPD), and to develop a global strategy for diagnosis, management and 
prevention of the disease [1]. Many of its recommendations are limited, however, because they are yet to be validated. These include recommendation 9 of the GOLD Executive Summary [1], which called for the development and evaluation of methods, in addition to spirometry, that could assess and monitor COPD; and recommendation 12, which advocated the development and evaluation of effective tools for physician education on the prevention, diagnosis and management of COPD.

There is considerable concern, especially in primary-care, about assessing the benefits of pharmacological intervention in COPD. Bronchodilators, for example, often have little influence on $\mathrm{FEV}_{1}$ or wheezing. Likewise, the effects of inhaled corticosteroids on exacerbation frequency and quality of life are difficult to detect during routine consultations. Consequently, by the nature of their consulting practice, primary-care physicians require an assessment that will measure even small or moderate treatment-related improvements in symptoms and lifestyle impairment of individuals. Such information could prompt physicians to modify treatment, improve concordance between physicians and their patients about treatment goals, and encourage patients to adhere more fully with their agreed treatment regimens.

This document considers the GOLD recommendations and evaluates options for a rapid assessment (designed to complement spirometric assessments) for primary-care physicians to monitor the success of prescribed COPD treatment. This article reports on the consensus reached by the participants at the meeting, and aims to stimulate discussion and further research.

\section{Considerations on the content of a COPD assessment}

It was identified that there was a need to assess the effectiveness of pharmacological intervention in primary-care, as well as the benefits of other interventions such as physical rehabilitation or smoking cessation. This should help clinicians make management decisions, and encourage patients to get involved in their own care. For example, what would be important from the patient's perspective must be balanced against what can be achieved by appropriate treatment. Intervention can improve many different outcomes (Table 1), only some of which patients will consider important.

A tool that concentrates on individual symptoms, though, may inadvertently divert attention from the importance of other patient-focused
Table 1 Outcomes of COPD other than FEV ${ }_{1}$ that can respond to intervention.

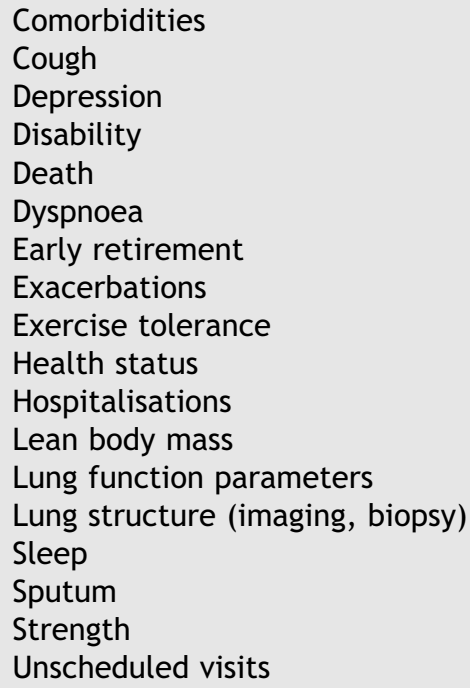

Outcomes considered by the participants to have demonstrated objective or subjective responses to therapy, as identified in the discussion meeting. No attempt has been made to assign relative value or importance to these outcomes, which are presented in alphabetical order.

\section{ctlce Alrways Group}

outcomes, such as the patient's ability to carry out daily activities and overall well-being. For example, by focusing only on breathlessness, a physician may fail to note that a patient is less tired or has more energy. Furthermore, assessing symptomatic response to treatment, such as a change in breathlessness, may require a reference level of activity that induces breathlessness (e.g. dressing, climbing stairs, carrying shopping, etc.). Patients might be aware of a change in breathlessness during only one of these activities, but judge the improvement to be worthwhile. For the same reasons, the new tool should not be treatment-specific, i.e. it should evaluate all effective interventions used to treat different stages of COPD. Proper symptom change evaluation may also be complicated by the nature of the symptom itself. For example, fatigue is very important for patients with COPD, but does not appear to respond readily to treatment, other than rehabilitation. In addition, other conditions including depression, breathlessness or frequent coughing, can also cause fatigue. Symptomatic benefit must, therefore, be defined and its relationship to physiological changes should be clarified.

Taking these points into consideration, the following list of characteristics of symptomatic improvement were considered as the most important for inclusion in a measurement tool for COPD. 
- Decrease in the need for additional reliever (or rescue) medication.

- Improvement in subjective sleep quality.

- Increase in quantity, quality or duration of daily activities.

- Reduction in time or extent of breathlessness at rest or with activity.

- Improvement in symptoms such as cough or sputum.

- Increase in the patient's subjective sense of well-being.

- Decrease in the frequency or duration of exacerbations (bad days).

\section{Considerations on the characteristics}

As well as the content of questions, there are other considerations for a tool to be suitable for general practice (Table 2 ). In primary-care, the physician has only a few minutes with each patient, so questions and questionnaires must be short and simple, so they can be completed quickly. Patients often have difficulty interpreting their own symptoms and understanding complex questionnaires. Questions should, therefore, be unambiguous, understandable and easily translated into different languages. Validation of any developed questionnaire is also essential. This may be more difficult than it seems: patients' answers often depend on emotional status and, to some extent, a desire to please their physician. Ideally, the results should be easy to interpret, and should direct subsequent treatment, for example, a simple algorithm for the best course of action. If these criteria are met, a tool is likely to be beneficial and cost-effective. Any such tool must also be durable and reproducible so that it will elucidate a similar response when used again by the same patient (when COPD remains stable)

Table 2 Essential requirements in a COPD assessment tool for primary-care use.

Speed and simplicity
Validity
Cost-effectiveness
Easy to use
Repeatable and reproducible
Capable of individualisation
Usable in different languages
Self-administered

Prerequisites for a primary-care tool, as identified by the participants of the discussion meeting. No attempt has been made to assign relative value or importance to each item. and when two different clinicians assess the same patient. Furthermore, it should reflect the unique way each patient benefits from different treatment regimes. Lastly, it should be non-ambiguous and avoid influences such as possible subjective interpretation by the clinician.

\section{Existing assessment scales}

Lung-function measurements do not reflect many aspects of COPD or its response to treatment that may be important to individual patients. These include physical or emotional status, levels of activity and perceptions of disability. As a result, several health-related quality-of-life (HRQoL) questionnaires that assess various aspects of quality of life or health status in respiratory medicine have recently been developed and validated (Table 3 ).

Thus far, a weak correlation has been detected between lung-function parameters and symptom scores as assessed by HRQoL scales [2,3]. One possible explanation may be that these scales assess many different aspects of a systemic disease, not just the direct effects of airflow limitation. Such HRQoL questionnaires are now an important part of evaluating efficacy/in clinical trials. Questionnaires that have been used in COPD include general health questionnaires, which apply beyond respiratory medicine (such as Medical Outcomes Study Short Form 36 [SF-36]), and those designed for respiratory conditions (Table 3). The role and validity of current health-status measurements for COPD have been extensively reviewed and a new instrument that evaluates disease control in COPD, the COPD Control Questionnaire (CCQ), is being developed $[4,5]$. The CCQ has three domains (symptoms, functional state and mental state) and includes questions considered important by both patients and respiratory physicians. It includes only ten items, for brevity and ease of use, and has recently been validated in a study with over 100 patients. Its use in primary-care and for individual patient assessment, however, has yet to be fully evaluated [5]. Other similar questionnaires are in a similar position, and many have no application to primary-care.

Williams et al. [6] provide a recent example of a modified health-status tool, in their self-reported version of the Chronic Respiratory Questionnaire (CRQ). Although the modified questionnaire's format differs, the structure, content and scoring of the self-reported version of the CRQ are the same as the original tool; the patient ticks an appropriate answer rather than being interviewed. In the dyspnoea part of the questionnaire, patients also 
Table 3 Questionnaires and instruments for the assessment of health-related quality of life in COPD.

\begin{tabular}{ll} 
Respiratory questionnaires & Reference \\
\hline ACQ: Asthma Control Questionnaire & {$[7]$} \\
AQ20: Airways Questionnaire 20 & {$[8]$} \\
BPQ: Breathing Problems Questionnaire & {$[9,10]$} \\
CCQ: COPD Control Questionnaire & {$[5]$} \\
CRQ: Chronic Respiratory Disease Questionnaire & {$[11]$} \\
LCADL: London Chest Activity of Daily Living Scale & {$[12]$} \\
OSAPOSI: Obstructive Sleep Apnea Patient-Oriented Severity Index & {$[13]$} \\
PFSDQ: Pulmonary Functional Status and Dyspnea Questionnaire & {$[14]$} \\
PFSS: Pulmonary Functional Status Scale & {$[15]$} \\
QOL-RIQ: Quality of Life for Respiratory Illness Questionnaire & {$[16,17]$} \\
SGRQ: St George's Respiratory Questionnaire & {$[18]$} \\
SOLQ: Seattle Obstructive Lung Disease Questionnaire & {$[19]$} \\
General Instruments used in COPD & \\
\hline EADL: Nottingham Extended Activity of Daily Living Scale & {$[20]$} \\
Nottingham health Profile & {$[21]$} \\
SF-36: Medical Outcomes Study Short Form 36 & {$[22]$} \\
SIP: Sickness Impact Profile & {$[23]$} \\
\hline
\end{tabular}

select their own answers, and rank and score the five most important activities. In a comparative trial of the self-reported version of the CRQ and the original interviewer-led CRQ, the investigators showed reasonably good agreement between the two, but the self-reported version was quicker and gave the patient more privacy. The Airways Questionnaire $30(\mathrm{AQ} 30)$ has also been modified for use in routine clinical practice; the shorter version is called the Airways Questionnaire 20 (AQ20) [8]. It comprises only 20 items (or questions) rather than 30 , with three possible answers: 'yes', 'no' and 'not applicable', it takes only 3 min to complete and can be self-administered. The AQ20 provides a simple and valid method for measuring health status in patients with asthma and COPD in routine practice. The shortened version of the Breathing Problems Questionnaire [10], comprises 10 questions that have principal application to pulmonary rehabilitation which are not specific for the primary-care setting. This environment requires questions of a more general nature.

\section{Proposals for the development of a primary-care physician's checklist}

A measurement tool that helps primary-care physicians assess response to therapy must detect improvements that result from treatment across all symptoms and physiological parameters. The requirements for a simple tool, however, conflict with the need for comprehensive coverage and very broad applicability, to suit all patients' needs, lifestyles, and sensitivity to change. It is, therefore, probably impossible to devise one measurement toot to satisfy all these needs. Using an assessment process sulch as an aide-mémoire or checklist comprising a few quick and simple questions, rather than an assessment toot, has therefore been considered. Such a checklist can be tailored to meet individual patient's needs and used to assess symptomatic benefit in clinical practice. The following questions are proposed:

- Describe any change?

This should then be followed by more focused questions:

- Describe any change in your daily activities that you judge to be worthwhile? " (alternatively: "Describe how able you are to perform more physical activities such as walking?" and/or "Describe how able you now are to perform more social activities such as going out with friends?"')

- Is there any change in breathlessness during activities?

- Has your cough changed?

- How much additional reliever (or rescue) medication are you now needing?

- Is there any change in your sleep pattern?

- Have you noticed any other improvements?

- Have you noticed any worsening?

- How do you feel overall as compared to before?

These, or similar developed questions could be asked after 'an appropriate treatment period' (at least 1 month of therapy, with 6 weeks as optimal, 
but worded to allow flexibility), and should be conducted during a clinician-patient interview.

\section{Summary and conclusions}

This paper discusses the need for a tool to assess benefits of treatment in COPD and presents the consensus reached by a group of respiratory and primary-care specialists with an interest in respiratory medicine. The GOLD recommendations called for the development and evaluation of methods, in addition to spirometry, that could assess and monitor COPD, and for physician education on the prevention, diagnosis and management of COPD. Since GOLD defined COPD as a progressive, and not fully reversible (in most cases poorly reversible) disease, spirometry alone cannot characterise the impact of treatment on the whole spectrum of COPD. Thus, there is a need for new methods that measure treatment success beyond $\mathrm{FEV}_{1}$ in COPD patients. Any such tools would not take the place of spirometry, but would complement lung-function measurements and be used for routine follow-up assessment.

Existing questionnaires are designed and validated for groups of patients with COPD,butare not currently suitable for assessing therapeutic benefit in individual patients. Unfortunately, no simple questionnaire can currently assess individual benefit reliably and sensitively; thus a standardised approach to symptomatic assessment is needed. Such an approach could be based on an aide-mémoire, or checklist, to help primary-care practitioners recognise symptomatic benefit. We have proposed such a checklist, and would welcome further discussion on its content, usefulness and validation.

There is now the need to validate this proposed questionnaire on COPD patients in primary-care settings in different countries. Following this it can be further refined.

\section{Acknowledgements}

The discussions and preparation of this paper were supported by an unrestricted educational grant from Novartis Pharma AG, Basel, Switzerland.

\section{References}

[1] Pauwels RA, Buist AS, Calverley PM, Jenkins CR, Hurd SS. GOLD Scientific Committee. Global strategy for the diagnosis, management, and prevention of chronic obstructive pulmonary disease. NHLBI/WHO global initiative for chronic obstructive lung disease (GOLD) workshop summary. Am J Respir Crit Care Med 2001;163(5):1256-76.

[2] Jones PW, Bosh TK. Quality of life changes in COPD patients treated with salmeterol. Am J Respir Crit Care Med 1997;155:1283-9.

[3] Ferrer M, Alonso J, Morera J, Marrades RM, Khalaf A, Agnar $M C$, et al. Chronic obstructive pulmonary disease stage and health-related quality of life. The Quality of Life of Chronic Obstructive Pulmonary Disease Study Group. Ann Intern Med 1997;127(12):1072-9.

[4] Jones PW. Health status measurement in chronic obstructive pulmonary disease. Thorax 2001;56:880-7.

[5] Van Der Molen T, Willemse BW, Schokker S, Ten Hacken NH, Postma DS, Juniper EF. Development, validity and responsiveness of the clinical COPD questionnaire. Health Qual Life Outcomes 2003;28(1):13.

[6] Williams JEA, Singh SJ, Sewell L, Guyatt GH, Morgan MDL. Development of a self-reported Chronic Respiratory Questionnaire (CRQ-SR). Thorax 2001;56:954-9.

[7] Juniper EF, O’Byrne PM, Guyatt GH, Ferrie PJ, King DR. Development and validation of a questionnaire to measure asthma control. Eur Respir J 1999;14:902-7.

[8] Barley EA, Quirk FH, Jones PW. Asthma health status measurement in clinical practice: validity of a new short and simple instrument. Respir Med 1998;92(10):1207-14.

[9] Hyland ME, Bott J, Singh S, Kenyon CA. Domains, constructs and the development of the Breathing Problems Questionnaire. Quality Life Res 1994;3:245-56.

[10] Hyland ME, Singh SJ, Sodergren SC, Morgan MP. Development of a shortened version of the Breathing Problems Questionnaire suitable for use in a pulmonary rehabilitation ctinic: a purpose-specific, disease-specific questionhaire. Quality Life Res 1998;7:227-33.

[11] Guyatt GH, Berman LB, Townsend M, Pugsley SO, Chambers LW. A measure of quality of life for clinical trials in chronic lung disease. Thorax 1987;42(10):773-8.

[12] Garrod R, Bestall JC, Paul EA, Wedzicha JA, Jones PW. Development and validation of a standardized measure of activity of daily living in patients with severe COPD: the London Chest Activity of Daily Living Scale (LCADL). Respir Med 2000;94(6):589-96.

[13] Piccirillo JF, Gates GA, White DL, Schectman KB. Obstructive sleep apnea treatment outcomes pilot study. Otolaryngol Head Neck Surg 1998;118(6):833-44.

[14] Lareau SC, Meek PM, Roos PJ. Additional testing of the modified pulmonary functional status, additional testing of the modified Pulmonary Functional Status And Dyspnea Questionnaire (PFSDQ-M): ease of use, stability, reliability and validity. Am J Respir Crit Care Med 1997;155(4 (Part 2)):A722.

[15] Weaver TE, Narsavage GL, Guilfoyle MJ. The development and psychometric evaluation of the Pulmonary Functional Status Scale: an instrument to assess functional status in pulmonary disease. J Cardiopulm Rehabil 1998;18:105-11.

[16] Maille AR, Kaptein AA, Koning CJ, Zwinderman AH. Developing a Quality-of-Life Questionnaire for patients with respiratory illness. Monaldi Arch Chest Dis 1994;49(1):76-8.

[17] Maille AR, Koning CJ, Zwinderman AH, Willems LN, Dijkman $\mathrm{JH}$, Kaptein AA. The development of the 'Quality-of-Life for Respiratory Illness Questionnaire (QOL-RIQ)': a disease-specific quality-of-life questionnaire for patients with mild to moderate chronic non-specific lung disease. Respir Med 1997;91(5):297-309.

[18] Jones PW, Quirk FH, Baveystock CM, Littlejohns P. A self-complete measure of health status for chronic airflow limitation. The St. George's Respiratory Questionnaire. Am Rev Respir Dis 1992;145(6):1321-7. 
[19] Tu SP, MCDonell MB, Spertus JA, Steele BG, Fihn SD. A New self-administered questionnaire to monitor health-related quality of life in patients with COPD. Ambulatory care quality improvement project (ACQUIP) investigators. Chest 1997;112(3):614-22.

[20] Okubadejo AA, O'Shea L, Jones PW, Wedzicha JA. Home assessment of activities of daily living in patients with severe chronic obstructive pulmonary disease on long-term oxygen therapy. Eur Respir J 1997;10(7):1572-5.
[21] Hunt SM, McEwen J, McKenna S. Measuring health status. London, UK: Croom Helm; 1986.

[22] Ware Jr JE, Sherbourne CD. The MOS 36-item short-form health survey (SF-36). I. Conceptual framework and item selection. Med Care 1992;30(6):47383.

[23] Pollard WE, Bobbitt RA, Bergner M, Martin DP, Gilson BS. The Sickness Impact Profile: validation of a health status measure. Med Care 1976;14(1):57-67.

Available online at www.sciencedirect.com

science@direct.

Available online at http://www.thepcrj.com

\section{Copyright General Practice Airways Group Reproduction Prohibited}

